\title{
Destinação de águas residuárias provenientes do processo de dessalinização por osmose reversa
}

\author{
Tales M. Soares ${ }^{1}$, Iran J. O. da Silva ${ }^{1}$, Sergio N. Duarte ${ }^{1}$ \& Ênio F. de F. e Silva ${ }^{2}$
}

\begin{abstract}
RESUMO
Nos últimos anos, inúmeros aparelhos de dessalinização por osmose reversa foram instalados no Brasil, sobretudo na Região Nordeste, onde se têm, historicamente, graves problemas econômicos e sociais devido à escassez de água. A dessalinização das águas pode constituir-se em uma ferramenta concreta de desenvolvimento regional no semi-árido do Nordeste brasileiro; entretanto, é necessário que se considerem os riscos ambientais decorrentes, isto porque, na dessalinização se gera, além da água potável, uma água residuária (rejeito), altamente salina e de poder poluente elevado. No presente texto são revisados trabalhos conduzidos no Brasil e em outros paises, os quais utilizam diversas alternativas para a destinação e o uso deste rejeito.
\end{abstract}

Palavras-chave: dessalinizador, rejeito, impacto ambiental, salinidade

\section{Disposal of wastewater from desalination process by reverse osmosis}

\begin{abstract}
During the last years, many desalination equipments by reverse osmosis were installed in Brazil, especially in Northeast Region, where, historically, serious socioeconomic problems exist due to water scarcity. Despite water desalinization be able to constitute a concrete tool for the development of Northeast Region, it is necessary to consider the consequent environmental risks, because in desalination process, besides the potable water a wastewater (reject), highly salty and pollutant is also generared. In the present article, studies conducted in Brazil and in other countries are revised which present alternatives for disposal and use of this reject.
\end{abstract}

Key words: desalter, reject, environmental impact, salinity

1 ESALQ/USP. Av. Pádua Dias 11, CP 9, CEP 13.418-900. Fone: (19) 3429-4147. E-mail: talesmiler@bol.com.br; ijosilva@esalq.usp.br; snduarte@esalq.usp.br; effsilva@esalq.usp.br

${ }^{2}$ Departamento de Tecnologia Rural/UFRPE. Rua Dom Manoel de Medeiros, s/n, CEP 52171-900, Recife, PE. Fone: (81) 3302 1261. E-mail: effsilva@uol.com.br 


\section{INTRODUÇÃO}

A escassez de água, seja quantitativa ou qualitativa, tem sido uma constante preocupação ao longo da História da humanidade, porém, a partir da última década do século XX, este problema ficou mais evidenciado devido ao crescimento populacional, à melhoria das condições de vida, o que demanda mais água, e à importância que os meios de comunicação têm dado ao tema, permitindo sua divulgação em todos os âmbitos (Juan, 2000).

A despeito de ser o Brasil o maior detentor mundial de água potável, com $8 \%$ das reservas mundiais, respondendo por $18 \%$ do potencial de água de superfície do planeta, ao se considerar, em lugar da disponibilidade absoluta de recursos hídricos renováveis, aquela relativa à população dele dependente, o País deixa de ser o primeiro e passa ao vigésimo terceiro do mundo, visto que, enquanto a Região Amazônica concentra 80\% dos recursos hídricos brasileiros, abrigando $7 \%$ da população, na Região Nordeste, que abriga $27 \%$ da população, apenas estão disponíveis 3,3\% desses recursos (Paz et al., 2000).

Em 1996, a demanda hídrica mundial estava estimada em $5.692 \mathrm{~km}^{3}$ ano $^{-1}$ contra uma oferta de $3.745 \mathrm{~km}^{3} \mathrm{ano}^{-1}$, ou seja, a oferta hídrica só atendia a cerca de $66 \%$ dos usos múltiplos. Mantendo-se as taxas de consumo e se considerando um crescimento populacional à razão geométrica de 1,6\% a.a., o esgotamento da potencialidade de recursos hídricos pode ser referenciado por volta do ano 2053; assim, as disponibilidades hídricas precisam ser ampliadas e, para tanto, são necessários investimentos em pesquisa e desenvolvimento tecnológico para exploração viável e racional da água (Maia Neto, 1997).

Certamente, em qualquer situação fisiográfica a depleção dos recursos hídricos deve ser avaliada com preocupação, mas, em regiões como o Nordeste do Brasil, caracterizada por um clima semi-árido, representado por altas temperaturas, elevadas taxas de evaporação e baixas precipitações pluviais, fatores que favorecem a escassez de água, a preocupação há de ter caráter iminente. Nesta região, a disponibilidade hídrica anual de 700 bilhões de $\mathrm{m}^{3}$ pode ser considerada expressiva; entretanto, como ressalvam Rebouças \& Marinho (1972), somente 24 bilhões de $\mathrm{m}^{3}$ permanecem efetivamente disponíveis, sendo que a maior parte, ou seja, 97\%, é consumido pela evaporação que atinge, em média, $2.000 \mathrm{~mm}$ anuais.

A Região Nordeste ocupa 18,27\% do território brasileiro, com uma área de 1.561.177,8 km²; desse total, 962.857,3 km² se situam no Polígono das Secas, delimitado em 1936 por meio da Lei 175 e revisado em 1951. O Polígono, que compreende as áreas sujeitas repetidamente aos efeitos das secas, abrange oito Estados nordestinos: o Maranhão é a única exceção, além de parte (121.490,9 km²) de Minas Gerais, na Região Sudeste; já o Semi-Árido ocupa 841.260,9 km² de área no Nordeste e outros $54.670,4 \mathrm{~km}^{2}$ em Minas Gerais e se caracteriza por apresentar reservas insuficientes de água em seus mananciais (SUDENE, 2004).

Ainda que a solução aos problemas da escassez de água no Nordeste seja uma meta há muito tempo almejada, inclu- sive constituindo a força motriz da primeira fase da história da irrigação no Brasil (Bernardo, 1992), continua-se verificando, atualmente, os impactos das estiagens sobre a população local, seja como reflexos econômicos substanciosos na agricultura, ou como prejuízos sociais, os quais se estendem, como conseqüência, às demais regiões do País.

Apesar da deficiência em recursos hídricos superficiais, poderiam ser extraídos do subsolo da Região Nordeste, sem risco de esgotamento dos mananciais, pelo menos 19,5 bilhões de $\mathrm{m}^{3}$ de água por ano (40 vezes o volume explorado hoje), segundo estudos da Associação Brasileira de Águas Subterrâneas (ABAS). O uso desta·água, porém, é limitado por um problema típico dos poços do interior nordestino: a concentração elevada de sais. Grande parte da região (788 mil km² , ou 51\% da área total do Nordeste) está situada sobre rochas cristalinas e o contato por longo tempo, no subsolo, entre a água e esse tipo de rocha, leva a um processo de salinização. Sem opção, diversas comunidades rurais nordestinas consomem água com salinidade acima do limite recomendado pela OMS, que é de 500 ppm. Nessas comunidades, a única fonte de água é o aqüífero cristalino subterrâneo (Carvalho, 2000).

Além de um recurso imprescindível à vida, a água também é um insumo de desenvolvimento. Associada às políticas públicas viciadas em corrupção, como historicamente praticadas na região, a escassez de água é um dos primordiais fatores de origem da miséria no Nordeste. Monteiro (2002) encontrou forte correlação entre indicadores socioeconômicos no Estado do Ceará e a salinização das águas que abastecem suas populações. Os 10 municípios (entre 170) com piores indicadores possuem quase $70 \%$ de seus poços com altos teores de sais, enquanto nos 10 melhores classificados este percentual é de apenas 16\%.

Em uma tendência observada há alguns anos, os Governos Federal e Estaduais têm procurado instalar equipamentos de dessalinização das águas salobras subterrâneas, objetivando a geração de água doce para o abastecimento urbano no Nordeste.

Em 2004, conforme dados da Associação dos Geógrafos Brasileiros, mais de 3 mil dessalinizadores estavam instalados no semi-árido do Nordeste. O Governo Federal, mediante a implantação do Programa Água Doce, do Ministério do Meio Ambiente, sinaliza a ampliação desse número, indicando ainda intenção de recuperar os equipamentos atualmente parados por falta de manutenção e mau uso (Associação dos Geógrafos Brasileiros, 2004).

Além do uso nos abastecimentos rural e urbano, tendo em vista a diminuição do preço dos dessalinizadores, pode-se prever sua utilização em empreendimentos agrícolas, sobretudo para aqueles implementados de forma intensiva e com culturas de alto valor. Soares et al. (2005), por exemplo, apresentam um trabalho envolvendo dessalinização de água salobra subterrânea para a produção de mudas cítricas, mostrando o crescimento significativamente superior das plantas irrigadas com água dessalinizada, em comparação com as irrigadas com a água salobra e com a água rejeito da dessalinização.

O método usado para a dessalinização no Nordeste tem 
sido, predominantemente, o processo de osmose reversa (Porto et al., 2004). Amorim et al. (2004b) atribuem o predomínio da osmose reversa à simplicidade e robustez do equipamento, aos baixos custos de instalação e operação, incluindo o consumo de energia e de mão-de-obra na operação, à capacidade de tratar volumes baixos a moderados de água bruta, à elevada taxa de recuperação, à continuidade do processo e à excelente qualidade da água tratada; entretanto, a osmose reversa implica na geração de rejeito, uma água residuária do processo e que tem concentração iônica majorada, ou seja, ao se dessalinizar a água salobra, transformando-a em água doce, gera-se um outro tipo de água, mais salina que a própria água salobra e, por conseguinte, com risco de contaminação ambiental elevado. Neste sentido, ainda que seja uma técnica incremental ao bem-estar das populações pobres do Nordeste, podendo constituir-se em uma concreta ferramenta ao desenvolvimento da região, deve-se ponderar pela dualidade do benefício da dessalinização por osmose reversa, tendo em vista o potencial de contaminação da água residuária gerada no processo. No presente texto, procurou-se revisar os trabalhos que, direta ou indiretamente, abordaram a destinação e o uso do rejeito da dessalinização por osmose reversa, objetivando-se contribuir para a organização das informações até então geradas.

\section{Dessalinização por osmose reversa}

A água se movimenta da condição de maior potencial para a condição de menor potencial, buscando o estado de equilíbrio (Libardi, 2005). Considerando que o potencial da água é dado pela Eq. 1, mantendo-se constantes os demais componentes, à exceção do potencial osmótico (Фos), a água se movimentará de onde o módulo de seu potencial osmótico for menor para onde for maior, já que este componente é sempre negativo.

$$
\Phi T=\Phi g+\Phi P+\Phi m+\Phi o s
$$

em que:

$$
\begin{aligned}
& \Phi \mathrm{t} \text { - potencial total } \\
& \Phi \mathrm{g} \text { - potencial gravitacional } \\
& \Phi \mathrm{P} \text { - potencial de pressão } \\
& \Phi \mathrm{m} \text { - potencial mátrico } \\
& \Phi \text { os - potencial osmótico }
\end{aligned}
$$

Quando uma solução diluída é colocada em contato com uma solução concentrada, ocorre a movimentação dos íons em direção à solução diluída e a movimentação de água pura em direção à solução mais concentrada. A este fenômeno se dá o nome de difusão. Quando a difusão se processa por meio de uma membrana semi-permeável, que deixa passar a água mas não os solutos, chama-se de osmose a saída da água pura em direção à água concentrada. A pressão necessária a ser aplicada para evitar a osmose, é chamada pressão osmótica a qual, conforme Juan (2000), é quantificada como a diferença de nível entre as duas soluções após se atingir o equilíbrio. Considerando-se que o interesse seja aumentar o volume da água pura (dessalinização), dever-se-ia aplicar uma pressão extra, superior à pressão osmótica, capaz de suplantar o potencial osmótico da solução mais concentrada, fazendo sair dela água pura em direção à solução menos concentrada. Como neste caso a água pura se estaria movimentando em sentido contrário ao sentido natural da osmose dá-se, a este processo, o nome de osmose reversa ou osmose inversa.

Para a dessalinização por osmose reversa, portanto, dois aspectos são fundamentais, de acordo com Juan (2000): a existência de fonte de energia para vencer o potencial osmótico da água salina, ou seja, para ‘inverter a direção’ que ocorreria na osmose, e a qualidade da membrana semi-permeável que irá separar os sais.

Para quantificar e qualificar as águas potável e rejeito, diversas equações são utilizadas. Mediante a Eq. 2, determina-se o percentual de recuperação de água potável (\%R), ou seja, quanto de água potável (Vp) se produz a partir de dado volume de água na alimentação do sistema (Va). Mediante a Eq. 3, por sua vez, avalia-se o percentual de rejeição de sais, isto é, a eficiência da membrana (\%E) em separar os sais da água de alimentação. Para aumentar a eficiência da dessalinização pode-se, além de utilizar membranas mais eficientes, trabalhar com diferentes estruturas de produção; para isto, como explica Juan (2000), pode-se organizar as membranas em paralelo e/ou em série.

$$
\begin{gathered}
\% \mathrm{R}=\frac{\mathrm{Vp}}{\mathrm{Va}} \times 100 \\
\% \mathrm{E}=\left(\frac{\mathrm{Cp}}{\mathrm{Ca}}-1\right) \times 100
\end{gathered}
$$

em que:

Cp - concentração de sais na água dessalinizada

$\mathrm{Ca}$ - concentração de sais na água a dessalinizar

Independente da eficiência da membrana e da estrutura instalada, o sistema de osmose reversa produzirá sempre a água potável, mas também a água residuária (rejeito, salmoura ou concentrado). Considerando-se o poder poluente do rejeito, altamente salino, deve-se almejar a melhor escolha para sua destinação, especialmente porque quase sempre os cursos d'água e o solo são os principais meios para sua disposição.

\section{Destinação dada ao rejeito em outros países}

Estima-se que a atual capacidade instalada de dessalinização no mundo seja superior aos 32,37 milhões de $\mathrm{m}^{3}$ por dia (Watson et al., 2003).

Diversas opções para dessalinização existem e sua escolha depende de considerações econômicas e ambientais. Conforme Watson et al. (2003), dentre os sistemas de dessalinização, a osmose reversa se destaca, tanto em número de instalações (68\% das instalações), quanto em percentual da capacidade instalada ( $44 \%$ da capacidade).

Conforme supracitado, mediante osmose reversa se tem a água dessalinizada como produto, mas também um sub-produto, ou seja, o rejeito.

Em geral, nos países desenvolvidos, o rejeito está sendo transportado para os oceanos ou injetados em poços de grande profundidade; todavia, outras alternativas estão sendo estudadas, como: bacias de evaporação, redução de volume do 
rejeito por plantas aquáticas, bacias de percolação e irrigação de plantas halófitas (Porto et al., 2001).

Conforme Mickley (2004b), a escolha da melhor opção para se dispor o rejeito da dessalinização deve atender, dentre outros fatores, às disponibilidades locais (terra, compatibilidade das águas receptoras e distância), às disponibilidades regionais (geologia, leis estaduais, geografia e clima), ao volume de concentrado, aos custos envolvidos, à opinião pública e à permissibilidade.

A emissão em águas superficiais é o método mais usado para destinação do rejeito da dessalinização. Segundo Mickley (2004b), esta opção é usual para todos os tamanhos de projeto mas pressupõe compatibilidade com as águas receptoras, podendo haver necessidade de diluição. Ainda que os custos desta destinação sejam relativamente baixos (Mickley, 2004a), deve-se atentar para o impacto sobre a vida aquática, nos rios e mares receptores.

Das grandes estruturas instaladas no mundo para dessalinização de águas marítimas, a principal destinação do rejeito é seu retorno ao mar; esta alternativa de disposição seria ideal, considerando-se o poder de diluição dos oceanos, porém, como alertam Hoepner \& Lattemann (2002), é conveniente considerar a fragilidade de cada ecossistema. O impacto da emissão do rejeito das Ilhas Canárias produz pouco efeito no Oceano Atlântico como um todo, ainda que possa prejudicar o ecossistema costeiro, já que se trata de um corpo d'água aberto e de grande poder de diluição. Certamente, conforme esses autores, o Mar Vermelho, um corpo d’água semi-fechado, caracterizado pela troca limitada de água com o oceano aberto e também pelo frágil habitat biológico, é mais sensível à emissão de rejeito. Para Einav et al. (2002), os prejuízos aos ecossistemas marinhos se devem não só à alta concentração do rejeito mas, também, à presença de compostos químicos que podem ser necessários ao pré-tratamento da água. Conforme Einav \& Lokiec (2003), em Israel, além do impacto na vida marinha, os danos ambientais das plantas de dessalinização de águas marítimas por osmose reversa, são: prejuízo ao uso do solo do litoral (praias ficam ocupadas), poluição decorrente do aumento do uso de energia, poluição de aqüíferos (se houver vazamentos nas tubulações) e poluição sonora.

Nos EUA, o rejeito da dessalinização vem sendo emitido principalmente nas águas superficiais (41\%), no esgoto (31\%) ou injetado em poços profundos (17\%). Dentre outras alternativas, também se dispõe o rejeito na terra (2\%) e em tanques de evaporação (2\%) (Mickley, 2004b); naquele país, as tendências futuras para instalações de grande e médio portes, conforme Mickley (2004b) seriam: diminuir as destinações para os rios, para os esgotos e para a terra, e aumentar as destinações para os oceanos, para os poços profundos e tanques de cristalização de sais (descarga zero). Para instalações de porte pequeno, localizadas no interior do continente, segundo o pesquisador, em virtude dos custos, a destinação do rejeito para oceanos e para poços profundos fica inviável, sendo tendência continuar emitindo em rios, em esgotos e no solo, além do uso de tanques de evaporação e cristalização.

O esgoto é a segunda principal destinação do rejeito da dessalinização de águas salobras nos EUA, mas esta destinação depende do volume e da composição do rejeito, pois pode prejudicar o tratamento do esgoto (Mickley, 2004a). Segundo Mickley (2004b), o deságüe no esgoto pode requerer pré-diluição, pré-tratamento, pagamento de impostos, além da necessidade da tubulação de acesso; além disto, explicam Glenn et al. (1998b), a emissão do rejeito em águas superficiais, incluindo esgoto, pode apenas deslocar o problema para longe do local de sua produção, razão pela qual os usuários à jusante são relutantes em aceitar o rejeito, até mesmo após sua diluição.

A injeção do rejeito em poços profundos, como praticada na Flórida, fica restrita, em viabilidade econômica, aos grandes projetos de dessalinização, dependendo também das características hidrogeológicas específicas de cada terreno (Mickley, 2004a).

Para as instalações de dessalinização localizadas no interior do continente, de onde o rejeito não pode ser economicamente transportado para o mar, ou usado na agricultura ou, ainda, em outras aplicações, sua destinação é um problema crítico para exploração de fontes de água salobra. Na região de Neveg, em Israel, a excelente insolação e a disponibilidade de terra a preços razoáveis, capacitam o uso de tanques de evaporação; entretanto, para reduzir o requerimento de terra e os custos de produção, é essencial desenhar o sistema de osmose reversa com fração de recuperação do produto a mais alta possível (Glueckstern \& Priel, 1996).

Tem-se que observar que os tanques de evaporação, concentrando o rejeito, fazem concentrar elementos como selênio, boro e metais pesados em níveis tóxicos (Ong et al., 1995). Esses tanques abrigam, freqüentemente, uma cadeia biológica alimentar ativa, a qual, além de concentrar elementos tóxicos em peixes e invertebrados, pode contaminar aves aquáticas (Hothem \& Ohlendorf, 1989). Glenn et al. (1998b), considerando que tanques de evaporação podem atrair e prejudicar a vida selvagem, testaram modelos para evaporadores de camada arenosa.

Outra alternativa para redução do rejeito seria o secamento em evaporadores ou tanques de solarização sob condições controladas (Hayes \& Kipps, 1992). Ahmed et al. (2003) confirmaram a viabilidade técnica de se tratar rejeitos de desalinização por osmose reversa em instalações de estrutura simples, usando a tecnologia de cristalização de sais. Com base em sua análise, esclareceu-se que vários tipos de sais, incluindo gesso, cloreto de sódio, hidróxido de magnésio, cloreto de cálcio, carbonato de cálcio e sulfato de sódio, podem ser produzidos. Esses produtos foram considerados de alta qualidade, estando na demanda de várias indústrias. Observam os autores que um estudo de viabilidade é necessário antes de se decidir precipitar sais de águas de rejeito.

A utilização de bacias de percolação, por sua vez, apesar de permitir a recarga dos aqüíferos subterrâneos aumentaria, provavelmente, sua concentração química, não sendo recomendada para disposição do rejeito.

A destinação do rejeito pela irrigação é usada principalmente para pequenos volumes (até $4 \mathrm{~m}^{3} \mathrm{~d}^{-1}$ ) nos EUA. Conforme Mickley (2004a), requer muita disponibilidade de terra 
e normalmente mistura com águas para diminuir a salinidade, ficando limitada pelo clima e pelas taxas de absorção do solo. O rejeito pode ser aplicado para culturas ou na vegetação, mediante aspersores ou por superfície, em substituição à água de melhor qualidade, aumentando sua conservação. Áreas de lazer, como gramados, parques e campos de golfe, além de espaços abertos e cinturões verdes de preservação ambiental, podem ser irrigados. Na Califórnia, informam Amorim et al. (2004b), pesquisas avaliam o uso de rejeito em sistemas construídos para serem o habitat de pássaros, peixes e plantas (“wetlands”).

Riley et al. (1997) consideraram o cultivo de plantas halófitas a melhor opção para dispor o rejeito da osmose reversa. Conforme Glenn et al. (1998b), a halófita Atriplex nummularia tem atributos desejáveis de uma cultura cicladora de rejeito: alto uso consuntivo da água para maximizar a absorção, alta tolerância aos sais para minimizar a fração de lixiviação requerida e elevada produtividade de biomassa, a qual tem utilidade forrageira. Informam Glenn et al. (1998a) que águas hipersalinas (> $\left.40.000 \mathrm{mg} \mathrm{L}^{-1}\right)$ têm sido usadas para irrigar, com sucesso, plantas halófitas.

Mais recentemente, o gênero Atriplex se tem destacado sob a perspectiva de desenvolver espécies apropriadas para irrigação com água do mar (Porto et al., 2001). Segundo Glenn et al.(1995), referenciados por Porto et al. (2001), 50 milhões de hectares podem ser trazidos para a produção agrícola, mediante a irrigação com água do mar, utilizando espécies halófitas, em especial a Atriplex nummularia.

\section{Destinação dada ao rejeito no Brasil}

Os trabalhos disponíveis na literatura quase sempre abordam a destinação do rejeito da dessalinização de águas marítimas e aqueles que abordam o rejeito oriundo de águas subterrâneas, se relacionam a grandes volumes. Ambas as situações diferem da atual realidade da dessalinização no Nordeste brasileiro, onde se dessaliniza águas salobras mediante dessalinizadores de pequeno porte; neste sentido, outras alternativas que não apenas as usuais devem ser avaliadas e propostas.

No Brasil, o rejeito não está recebendo, na quase totalidade dos casos, qualquer tratamento; mesmo assim, está sendo despejado no solo, propiciando alto acúmulo de sais nas camadas superficiais do terreno (Porto et al., 2001). A deposição deste rejeito poderá trazer, em curto espaço de tempo, sérios problemas para as comunidades que se beneficiam da tecnologia de dessalinização, como informam Porto et al. (1999).

Um estudo no município de Petrolina, Estado de Pernambuco, confirmou a salinização do solo causada pelo despejo indiscriminado dos efluentes de dois dessalinizadores instalados em duas comunidades (Amorim et al., 1997). No Estado do Ceará, Pessoa (2000) verificou que, somente em Canindé, em 25\% das localidades estudadas foram observados problemas de erosão e salinidade nos solos que recebem os rejeitos.

Pinheiro \& Callado (2004), também no Estado do Ceará, verificaram, considerando 79 comunidades com dessalinizadores em operação, que apenas 20\% aproveitavam os rejeitos, muito embora sem qualquer fundamentação técnico-científica ou econômica para o seu uso; segundo eles, lavagem de roupa e automóveis constituem a maior freqüência em utilização dos rejeitos (38\%), não se podendo afirmar que as referidas práticas tragam benefício significativo às pessoas, sendo apenas experiências isoladas e motivadas pela absoluta falta de água de boa qualidade. Atividades estritamente econômicas têm sido fruto de exclusiva curiosidade dos produtores, embora alguns projetem a exploração da tilápia vermelha e do camarão com o uso dos rejeitos; entretanto, predomina a drenagem dos rejeitos para terrenos próximos ao sistema e para os cursos d’água (60\%), sendo esta a forma mais prática e de baixo custo de descartá-los. Quanto ao retorno do rejeito para o poço, verificado em $9,5 \%$ das comunidades, talvez fosse interessante, conforme os autores, aprofundar pesquisas sobre os limites de salinidade que permitissem sua eventual reciclagem. Concluem os autores, pelas pequenas vazões observadas nas comunidades pesquisadas, que os impactos no ambiente decorrentes do rejeito podem, ser considerados desprezíveis.

Amorim et al. (2004b), entretanto, reforçam que esses rejeitos possuem potencial para contaminar mananciais, solo e até a fauna e flora da região, alertando que os sais depositados na superfície do solo, além de contaminarem mananciais subterrâneos, poderão ser transportados pela ação dos ventos ou pela água de escoamento superficial e salinizar aguadas e áreas próximas. O sódio dos sais, por exemplo, poderá substituir o cálcio nos sítios de troca de cátions, causando a dispersão dos colóides do solo, contribuindo para redução da sua condutividade hidráulica. Conseqüentemente, segundo acrescentam os autores, a vegetação da área seria prejudicada devido à deterioração das características físico-químicas dos solos e aos efeitos negativos dos sais sobre a fisiologia das plantas. Com a destruição do estrato herbáceo, os rebanhos e os animais silvestres seriam seriamente prejudicados pela falta da pastagem natural e de abrigo.

Como alternativa ao rejeito gerado pela dessalinização por osmose reversa, Amorim et al. (2004b) apontaram o uso da evaporação solar para a cristalização dos sais dissolvidos, reduzindo o volume dos efluentes líquidos, transformandoos em produto sólido, o que reduz o contato com o solo e facilita o manuseio. A obtenção de sais cristalizados decorre da evaporação da água, por intermédio da precipitação dos sais, quando estes atingem seus pontos de solubilidade. Os pesquisadores observaram o predomínio dos sais sódicos, seguidos dos magnesianos e, por último, dos cálcicos. Mesmo considerando as impurezas nos sais que se cristalizaram e que podem tornar proibitivo o consumo, vislumbraram a necessidade de estudos de viabilidade devido a sua importância fundamental, não apenas para o setor de suplementação mineral humana e animal mas, também, no industrial, principalmente pela predominância do $\mathrm{NaCl}$.

A técnica da cristalização de sais utiliza, a seu favor, a elevada demanda evaporativa da atmosfera característica do Nordeste; mas, considerando que nem sempre seria interessante perder água por evaporação, trabalhos também focalizam o uso do rejeito como efluente líquido. Em outro 
estudo, Amorim et al. (2004a), avaliando os efluentes líquidos para a criação da Tilápia koina (Oreochromis sp.), em águas com condutividade elétrica que variou de 9,46 a $12,7 \mathrm{dS} \mathrm{m} \mathrm{m}^{-1}$ observaram, após seis meses, que a sobrevivência da citada espécie foi de 91,50\%, valor este dentro dos padrões normais de cultivo (cerca de $85 \%$ ), indicando que as condições ecológicas do reservatório foram boas, permitindo, inclusive, a reprodução dos indivíduos; constataram, também, que além de condições permissíveis de vida houve ganho de peso (de 3,2 para 276,73 g por indivíduo), e que este ganho só não foi maior em virtude de não ter sido realizada renovação do efluente nos tanques durante o cultivo; concluem eles que o cultivo de tilápias vermelhas, do gênero Oreochromis traz, como conseqüências positivas, a alta qualidade do pescado com relação ao sabor e à aparência do peixe além da possibilidade de ofertar alimento de bom valor nutritivo às populações do semi-árido, sendo uma alternativa com grandes potencialidades de viabilidade econômica mas cuja escala de exploração depende do potencial de produção de rejeito por dia.

Dubon \& Pinheiro (2004) observaram resultados também promissores ao investigar o crescimento da tilápia vermelha Oreochromis sp, em água de maré, de salinidade final de $36.000 \mathrm{mg} \mathrm{L}^{-1}$. Além da piscicultura, a carcinicultura também vem sendo empregada no aproveitamento da água de rejeito. Um grupo de pesquisa da EMBRAPA investiga a viabilidade de criação de camarão (Panaeus vannamei).

Uma outra linha de pesquisa em desenvolvimento no Brasil com o objetivo de se aproveitar o rejeito da dessalinização, consiste em se empregar espécies halófitas, dentre as quais a erva-sal (Atriplex nummularia) é uma das mais importantes. A erva-sal foi introduzida no Nordeste brasileiro por intermédio da Inspetoria Federal de Obras Contra as Secas, na década de 30; todavia, só agora esta planta está despertando o interesse dos pesquisadores brasileiros. Por ser originário de regiões áridas, o gênero Atriplex se vem destacando há algumas décadas, principalmente por conseguir produzir e manter uma abundante fitomassa, mesmo em ambientes de alta aridez e salinidade, adaptando-se muito bem a regiões com precipitação ao redor de 100 a $250 \mathrm{~mm}^{\mathrm{ano}}{ }^{-1}$ (Porto et al., 2001). Estes autores notaram produção de matéria seca de $9.436 \mathrm{~kg} \mathrm{ha}^{-1}$ no cultivo da Atriplex no Nordeste brasileiro, computando a retirada de $1.145 \mathrm{~kg} \mathrm{ha}^{-1}$ de sais, o que correspondeu, considerando-se a aplicação de $29.117 \mathrm{~kg} \mathrm{ha}^{-1}$ de sais aplicados no solo via irrigação com água de rejeito, a uma eficiência de extração de apenas 3,93\%. A despeito da baixa eficiência registrada para um ciclo de 378 dias, os autores ressalvam que outros estudos devem ser conduzidos com a Atriplex nas condições brasileiras.

Em uma outra linha de pesquisa, Soares et al. (2005), averiguando a influência de águas salinas no crescimento de mudas cítricas, observaram que o rejeito prejudicou o desenvolvimento radicular e o acúmulo de matéria seca das plantas, em comparação com plantas irrigadas com água dessalinizada; entretanto, mudas de laranjeira, uma das espécies mais sensíveis aos sais (Ayers \& Westcot, 1999), puderam ser produzidas (Soares et al., 2005), sinalizando a alternativa de se produzir, mediante a irrigação com o rejeito, mu- das de plantas ornamentais, florestais e frutíferas, entre outras, as quais, quando comercializadas expedirão consigo os íons acumulados no substrato de cultivo potencializando, assim, a diluição dos sais no ambiente. Além da exportação dos sais, esta prática permitiria maior geração de divisas para a comunidade. Outros projetos públicos relacionados ao paisagismo e ao reflorestamento, por exemplo, poderiam pagar pela aquisição das plantas. Além da possibilidade de dirigir a produção para espécies mais tolerantes aos sais, a precocidade também deve constituir-se uma característica desejável das espécies produzidas. Em outro trabalho, Soares (2003) não mensurou prejuízos ao crescimento de porta-enxertos cítricos quando submetidos a irrigação com o rejeito, em comparação com a água dessalinizada, o que se atribuiu, em parte, ao rápido crescimento das plantas. Esta alternativa de se produzir mudas e plantas em recipientes, seria especialmente factível ao se assumir as preconizações de manejo para águas salinas, como apresentado por Rhoades et al. (2000). A estratégia de manejo poderia envolver irrigações sub-copa, localizadas e freqüentes, mas com lixiviação mínima ou nula, devendo ser concordante com as disponibilidades regionais de tipos de substrato, de tipos de recipientes de cultivo e de espécies de interesse comercial ou ecológico. O uso de sombreamento poderia, também, ser investigado para tolerância específica de cada espécie. Além da tolerância aos sais e da demanda por um mercado consumidor, na escolha das espécies a cultivar se deveria priorizar o alto consumo de água pelas plantas, pois quanto maior o consumo de água maior a lâmina de irrigação e, por conseguinte, maior também a quantidade de sais aplicada no recipiente. Maior, então, seria a extração/exportação de sais pelas plantas.

\section{CONCLUSÕES}

1. A dessalinização de águas marítimas ou salobras é uma realidade no mundo e no Brasil.

2. Diversas opções para dessalinização existem e sua escolha depende de considerações econômicas e ambientais.

3. Dentre os sistemas de dessalinização, a osmose reversa se destaca, em número de instalações e capacidade instalada, tanto no mundo quanto no Brasil.

4. Assim como nos demais sistemas, na dessalinização por osmose reversa se tem a água dessalinizada como produto, mas também um sub-produto, o rejeito.

5. Diferente de outros países, no Brasil a dessalinização de águas se processa mediante o uso de instalações de pequena capacidade. Ainda assim, deve-se ponderar pelos riscos de contaminação ambiental, decorrente da destinação do rejeito.

6. Assumindo a assertiva de que a água é um insumo de desenvolvimento, deve-se zelar pela viabilidade da dessalinização no País, seja para não se incorrer no equívoco dos que consideram modernização como sinonímia de desenvolvimento.

7. Além da credibilidade do poder público, o sucesso da dessalinização passa pela emancipação das comunidades nordestinas, não apenas dos eventos naturais das secas, mas 
também da verdadeira indústria da miséria historicamente assentada na região. Iniciativas que permitam a alforria dessas comunidades devem ser preservadas.

8. Como tecnologia emancipadora, a dessalinização, portanto, deve ser amparada pelas instituições de desenvolvimento regional, também para anular ou mitigar os efeitos do rejeito sobre o meio ambiente, concordando com a opinião pública e os interesses das comunidades.

9. Considerando as características da dessalinização no Brasil, mostram-se corretas as alternativas de linhas de investigação conduzidas pelos pesquisadores no País para destinação do rejeito, sobretudo as que tratam da aqüicultura e da descarga zero.

10. Ainda que uma alternativa a ser melhor investigada, o uso do rejeito para irrigação de plantas halófitas forrageiras pode ser incompatível com a seguridade ambiental em razão da ineficiência de extração de sais dessas plantas frente ao montante aplicado ao solo.

11. Uma outra alternativa merecedora de investigações é o cultivo de plantas halófitas e de plantas tolerantes aos sais, em recipientes de cultivo. Ao se comercializar e expedir essas plantas, evitar-se-ia o acúmulo dos sais no ambiente, pois estes seriam levados com o recipiente de cultivo. Nesta alternativa, quanto menor a lixiviação e quanto maior a precocidade da planta, maior seria a retirada de sais do ambiente. Portanto, a depender da rotatividade dos lotes cultivados, plantas de menor tolerância aos sais, inclusive as sensíveis, poderiam ser mais interessantes que aquelas tolerantes ou halófitas.

\section{LITERATURA CITADA}

Ahmed, M.; Arakel, A.; Hoey, D.; Thumarukudy, M. R.; Goosen, M. F. A.; Haddabi, M. A.; Belushi, A. A. Feasibility of salt production from inland RO desalination plant reject brine: a case study. Desalination, Amsterdam, v.158, n.1-3, p.109-117, 2003.

Amorim, M. C. C.; Porto, E. R.; Araújo, O. J.; Silva Júnior, L. G. Alternativas de reuso dos efluentes da dessalinização por osmose inversa: evaporação solar e meio líquido para cultivo de tilápia koina (Oreochromis sp.). http://www.cepis.ops-oms.org/ indexpor.html. 10 Jul. 2004a.

Amorim, M. C. C.; Porto, E. R.; Silva Júnior, L. G. A. Evaporação solar como alternativa de reuso dos efluentes da dessalinização por osmose inversa. http://www.cepis.org.pe/bvsaidis/ aresidua/i-007.pdf. 10 Jul. 2004b.

Amorim, M. C. C.; Silva Júnior, L. G. A.; Porto, E. R. Efeito de sais no solo provenientes de rejeitos da dessalinização por osmose inversa no semi-árido Pernambucano. In: Congresso Brasileiro de Engenharia Agrícola; 26, 1997, Campina Grande. Anais... Campina Grande: SBEA, 1997. CD Rom.

Associação dos Geógrafos Brasileiros. Embrapa utiliza rejeito de dessalinizadores para criar peixes e caprinos. http:// geocities.yahoo.com.br/agbcg/dessali.htm. 10 Jul. 2004.

Ayers, R. S.; Westcot, D. W. Qualidade de água na agricultura. Campina Grande: UFPB, 1999. 153p. FAO. Estudos de Irrigação e Drenagem, 29
Bernardo, S. Desenvolvimento e perspectiva da irrigação no Brasil. Engenharia na Agricultura, Viçosa, v.1, n.14, p.1-14, 1992.

Carvalho, P. Água potável via energia solar. Ciência Hoje, Rio de Janeiro, v.27, n.158, p.72-74, 2000.

Dubon, J. A. M.; Pinheiro, J. C. V. Aproveitamento de águas residuais provenientes de dessalinizadores instalados no Estado do Ceará. http://www.aguabolivia.org/situacionaguaX/IIIEncAguas/contenido/trabajos_verde/TC-115.htm. 10 Jul. 2004.

Einav, R.; Hamssib, K.; Periyb, D. The footprint of the desalination processes on the environment. Desalination, Amsterdam, v.152, n.1-3, p.141-154. 2002.

Einav, R.; Lokiec, F. Environmental aspects of a desalination plant in Ashkelon. Desalination, Amsterdam, v. 156, n.1-3, p. 79-85. 2003.

Glenn, E. P.; Brown, J; O’leary, J. Irrigating crops with seawater. Scientific American, New York, v.279, n.2, p.76-81, 1998a.

Glenn, E. P; Thompson, T. L.; Miyamoto, S. Halophyte crops and a sand-bed solar concentrator to reduce and recycle industrial, desalination and agricultural brines. Tucson: United States Department of the Interior. 78p. 1998b. Desalination Research and Development Program Report N. 35.

Glueckstern, P.; Priel, M. Optimized brackish water desalination plants with minimum impact on the environment. Desalination, Amsterdam, v.108, n.1-3, p.19-26. 1996.

Hayes, D.; Kipps, J. Salt-gradient solar ponds from concentrated subsurface agricultural drainage waters of the San Joaquin Valley, California. Desalination, Amsterdam, v. 88, n.1-3, p.301-309. 1992.

Hoepner, T.; Lattemann, S. Chemical impacts from seawater desalination plants: a case study of the northern Red Sea. Desalination, Amsterdam, v.152, n.1-3, p.133-140. 2002.

Hothem, R.; Ohlendorf, H. Contaminants in foods of aquatic birds at Kesterton Reservoir, California, 1985. Archives of Environmental Contamination and Toxicology, New York, v.18, n.6, p.773-786. 1989.

Juan, J. A. M. S. Desalación de aguas salobres y de mar. Osmose inversa. Madrid: Mundi-Prensa. 395p. 2000.

Libardi, P. L. Dinâmica da água no solo. Piracicaba: EDUSP. 2005. 344p.

Maia Neto, R. F. Água para o desenvolvimento sustentável. A Água em Revista, Belo Horizonte, v.9, p.21-32, 1997.

Mickley, M. C. Membrane concentrate disposal: practices and regulation. Denver: U.S. Department of the Interior. (Desalination and Water Purification Research and Development Program Report No.69). http://www.usbr.gov/pmts/water/media/ pdfs/report069.pdf. 10 de jul. 2004a.

Mickley, M. C. Desalination concentrate management and issues in the United States. http://www.twdb.state.tx.us/Desalination/ Desal/proceedings/Mickley.pdf. 10 Jul. 2004b.

Monteiro, V. P. Critérios para implantação de tecnologias de abastecimento de água potável em regiões afetadas pelo alto teor de sal. Fortaleza: UFC, 2002. 56p. Dissertação Mestrado

Ong, C.; Tanji, K.; Dahlgren, R.; Smith, G.; Quek, A. Water quality and trace element evapoconcentration in evaporation ponds for agricultural waste water disposal. Journal of Agricultural and Food Chemistry, Washington, v.43, n.7, p.1941-1947. 1995. 
Paz, V. P. da S.; Teodoro, R. E. F.; Mendonça, F. C. Recursos hídricos, agricultura irrigada e meio ambiente. Revista Brasileira de Engenharia Agrícola e Ambiental, Campina Grande, v.4, n.3, p.465-473, 2000

Pessoa, L. C. C. Análise de desempenho e do impacto ambiental dos dessalinizadores por osmose reversa. Fortaleza: UFC, 2000. 94p. Dissertação Mestrado

Pinheiro, J. C. V.; Callado, S. M. G. Avaliação de desempenho dos dessalinizadores do Ceará. http://www.bnb.gov.br/progEventosBN/projForumEconomia2003/DOCS/MESA\%2009\%20\%2034.PDF.10 Jul. 2004

Porto, E. R.; Amorim, M. C. C. de; Araújo, O. J. Potencialidades da erva-sal (Atriplex nummularia) irrigada com o rejeito da dessalinização de água salobra no semi-árido brasileiro como alternativa de reutilização. http://www.cepis.ops-oms.org/bvsaidis/aresidua/x-003.pdf. 10 Jul. 2004.

Porto, E. R.; Amorim, M. C. C. de; Araújo, O. J.; Silva Júnior, L. G. A. Aproveitamento dos rejeitos da dessalinização. In: Simpósio sobre captação de água de chuva no semiárido brasileiro, 1., 1997, Petrolina. A captação de água de chuva: base para viabilização do semi-árido brasileiro. Anais. Petrolina: Embrapa Semi-Árido/IRPAA/IRCSA, 1999. p.51-57.

Porto, E. R.; Amorim, M. C. C. de; Silva Júnior, L. G. A. Uso do rejeito da dessalinização de água salobra para irrigação da erva-sal (Atriplex nummularia). Revista Brasileira de Engenharia Agrícola e Ambiental, Campina Grande, v.5, n.1, p.111-114, 2001.
Rebouças, A. C.; Marinho, M. E. Hidrologia das secas do Nordeste do Brasil. Recife: SUDENE - DRN, Divisão de Hidrologia, 1972. 126p.

Rhoades, J.; Kandiah, A.; Mashali, A. M. Uso de águas salinas para produção agrícola. Trad. H. R. Gheyi, J. R. Sousa, J. E. Queiroz. Campina Grande: UFPB, 2000. 117p. FAO. Estudos de Irrigação e Drenagem, 48

Riley, J. J.; Fitzsimmons, K. M.; Glenn, E. P. Halophyte irrigation: an overlooked strategy for management of membrane fraction concentrate. Desalination, Amsterdam, v.110, n.3, p.197211. 1997.

Soares, T. M. Desenvolvimento de três porta-enxertos cítricos utilizando águas salinas. Piracicaba: ESALQ/USP, 2003. 94p. Mestrado

Soares, T. M.; Duarte, S. N.; Graf, C. C. D.; Zanetti, M.; Zocchi, S. S. Produção de mudas cítricas utilizando águas salinas. In: Congresso Nacional de Irrigação e Drenagem; 15, 2005, Teresina. Anais... Teresina: ABID, 2005. Cd Rom.

SUDENE - Superitendência de Desenvolvimento do Nordeste. O Nordeste semi-árido e o polígono das secas. http:// www.sudene.gov.br. 10 Jul. 2004.

Watson, I. C.; Morin Jr., O. J.; Henthorne, L. Desalting handbook for planners. Denver: United States Department of the Interior. 3.ed. 2003. 310p. Desalination and Water Purification Research and Development Program Report N. 72 